\title{
ASSESSMENT OF TUMOUR VASCULARITY BY TRANSVAGINAL COLOUR DOPPLER ULTRASOUND: A NOVEL PROGNOSTIC FACTOR OF CANCER CERVIX
}

\author{
Mangla $\mathbf{M}^{1}$, Singla $\mathrm{D}^{2}$
}

\section{Abstract}

Background: Ransvaginal Color Doppler Ultrasound is proposed as a novel prognostic tool in women with cervical cancer. We evaluated the assessment of tumour vascularity as a prognostic factor and its correlation with other well-known prognostic factors such as tumour size, parametrial invasion and lymph node status determined by MRI.

Method: Transvaginal Colour Doppler Ultrasound (TVCDUS) was used to assess vascularity of tumour among 56 patients with histologically proven cervical carcinoma. A visual analyzing system of 1 to 5 was used to grade vascularity. Correlation between the visual grading of vascularity and size of lesion, lymphadenopathy and stromal invasion were studied.

Result: All patients who had a tumour volume of $>0.1 \mathrm{~cm}^{3}$ had abundant vascularisation (a vascularity of 4 or more on visual grading). Thirteen out of 15 patients who had lymphadenopathy had a visual grading of vascularity of 4 or more. Out of 45 patients who showed parametrial invasion 20 had a visual grading of vascularity of $\geq 4$.

Conclusion: The vascularity of tumour as assessed by TVCDUS correlated very well with well established prognostic factors of cancer cervix such as lymphadenopathy, parametrial invasion and size of tumour mass lesion. Transvaginal colour Doppler ultrasound is a useful non-invasive method to assess tumour vascularity, which has some value in predicting prognosis.

\section{BACKGROUND}

Cervical cancer is the second most common cancer diagnosed among women after breast cancer. Almost $70 \%$ of the global burden falls in areas with lower levels of development and more than one fifth of all new cases are diagnosed in India ${ }^{1}$. As per estimates of 2012, around 122,844 new cases of cervical cancer are diagnosed every year in India ${ }^{2}$.

Timely and cost effective assessment of such patients is essential for proper

${ }^{1}$ Assistant Professor, Department of Obstetrics and Gynaecology. Gian Sagar Medical College, Ramnagar, Banur, Patiala, Punjab.

${ }^{2}$ Assistant Professor, Department of Anaesthesia BPS Govt Medical College, Khanpur-Kalan, Sonipat, Haryana

\section{Correspondence: Dr. Mishu Mangla}

E-mail: - deepak10.4u@gmail.com

Competing interests -none treatment. The factors, which are important to determine the extent of cervical carcinoma, include the size of tumour, its extension, histopathology, invasion of vascular space and the lymph node status. Of these, the growth of new blood vessels or angiogenesis has been known to be a very important factor in the growth and spread of any cancer ${ }^{3}$. Previous studies have shown this to be a very good prognostic factor in a variety of cancers including cutaneous melanoma $^{4}$, breast cancer ${ }^{5,6}$, and cervical carcinoma ${ }^{6}$. But majority of these have been done retrospectively on tissue specimens obtained after surgery.

It was hypothesised that a noninvasive method like transvaginal colour Doppler which can be used to assess tumour vascularity, may help to determine the growth and invasive potential of a tumour. This study was conducted to evaluate the role of transvaginal colour Doppler ultrasound in assessing vascularity of the tumour as a prognostic factor and to study its correlation with the other well-known prognostic factors such as tumour size, parametrial invasion and lymph node status determined by magnetic resonance imaging (MRI).

\section{MATERIALS AND METHODS}

This cross-sectional study was carried out at the Gynae-oncology unit, Department of Obstetrics \& Gynaecology, in SMS medical college and hospital, Jaipur, Rajasthan, from January 2009 to January 2010. A total of 56 patients with histologically proven locally advanced carcinoma of cervix were included in the study. Staging of cervical carcinoma was carried out on the basis of FIGO Staging System 2009 by examining the spread of lesion by pelvic examination and MRI. Initially a general grey scale transabdominal ultrasound scan assessment was undertaken with a full urinary bladder. The uterus, bilateral adnexa, cervical region and adjacent bladder wall were visualised. With the patient placed in lithotomy position, the transvaginal ultrasound probe was introduced and cervical region was brought in focus and examined for the size of the mass, echotexture, and contour of lesion. Presence or absence of free fluid, lymphadenopathy, and stromal invasion were also noted.

Tumour vascularity was assessed by transvaginal colour Doppler ultrasound (TVCDUS). A colour Doppler ultrasound machine with a $5-8 \mathrm{MHz}$ transvaginal transducer was used for all examinations. The high pass filter was set at $6 \mathrm{~Hz}$ in order to eliminate low frequency signals caused by vessel wall motion. Blood flow signals were measured from both ascending and descending branch of uterine artery. Cervix was then thoroughly examined and 
several Doppler signals were recorded from within the wall and around the cervical canal. A visual analysing scale from 1 to 5 graded the blood flow in and around the mass lesion, and the degree of vascularity: -

- Grade 1 - corresponds to our findings of blood flow in the normal postmenopausal uterus.

- Grade 2 - slightly increased amount of vascular tissue.

- Grade 3 - moderately increased amount of vascular tissue.

- Grade 4 - highly increased amount of vascular tissue.

- Grade 5 - almost completely covered with arteries and veins of different calibre.

An average of 5 recordings were taken from within the cervix. In addition, the flow velocity waveforms of blood vessels in and around the tumour were recorded. All measurements were taken with an angle of insonation $<60$ 。 and the sonograms were evaluated by a single observer in order to eliminate inter-observer variation.

All the data was entered in an Excel database and analysed using XL Stat and Stat Cal Software. The analysis included the assessment of correlation between the visual grading of vascularity and size of mass lesion, lymphadenopathy and stromal invasion.

Informed consent was obtained from all subjects prior to inclusion in the study. Patients were free to make a decision whether to participate in the study and study participation did not alter the usual clinical management. The study was approved by the institutional ethics committee.

\section{RESULTS}

The age and FIGO staging of patients included in the present study has been shown in table 1 . The majority of cases were over the age of 50 years. There were 31 patients with stage II disease, of which 11 were with stage IIa and 20 with stage IIb disease. 25 patients were with stage III disease, where IIIa and IIIb each constituting 4 and 21 patients respectively.

In this study population, 27 patients had a tumour volume of $<0.04 \mathrm{~cm}^{3}$. Out of these 15 had a visual grading of vascularity less than 3 . Only 7 (25.93\%) out of these had a visual grading of 4 or more. Interestingly all patients who had a tumour volume of $>0.1 \mathrm{~cm}^{3}$ had abundant vascularisation giving a visual grading of 4 or more (Table 2). The vascularity correlated well with the tumour size. 13 of the 15 patients $(86.66 \%)$ with lymphadenopathy had a visual grading of vascularity of $\geq 4$. Among the 41 patients who had lymph node negative disease, 24(58.54\%) had a visual grading of either 1 or 2. However, among the 45 patients who showed parametrial invasion $20(44.44 \%)$ had a visual grading of vascularity of 4 or more. Similarly, 6 of the 11 patients $(54.54 \%)$ with negative parametrial invasion had a vascularity grading of 1 or 2 .

\section{DISCUSSION}

Neovascularisation or development of new blood vessels is a well known factor in the growth and progression of cancers. It is associated with tumour growth, resistance to chemotherapy and the development of invasive and metastatic ability ${ }^{7}$. Reliable non-invasive procedures such as Colour Doppler ultrasound, which enables us to assess the tumour vascularity, would thus be very valuable in the prognostic characterization of patients since the extent of vascularity measured by Doppler correlates well with other markers of tumour growth and metastasis.

Previous studies indicate that the induction of angiogenesis can occur in two ways. It is either through mutations which activate oncogenes or through mutations inhibiting the functions of tumour suppressor genes ${ }^{8,9}$. It is known that in larger tumours, the blood supply is compromised as the tumour increases in size. Cellular hypoxia is one of the major factors initiating the mechanism of angiogenesis. Low oxygen concentration induces the synthesis of angiogenic factors, including HIF (hypoxia-inducible factor), within the cell ${ }^{10}$. It is also associated with an increase in the activity of the gene encoding vascular endothelial growth factor (VEGF), which is considered the strongest and a key promoter of angiogenesis ${ }^{11}$. This probably may

Table 1: Distribution of the study sample according to age and tumour stage

\begin{tabular}{|c|c|c|c|c|c|}
\hline \multirow{2}{*}{$\begin{array}{c}\text { Age } \\
\text { (in yrs) }\end{array}$} & \multicolumn{4}{|c|}{ Stage } & \multirow{2}{*}{ Tota } \\
\hline & II A & IIB & III A & IIIB & \\
\hline $30-39$ & $\begin{array}{c}2 \\
(40.00) \\
\end{array}$ & $\begin{array}{c}3 \\
(60.00) \\
\end{array}$ & $\begin{array}{c}0 \\
(0.00)\end{array}$ & $\begin{array}{c}0 \\
(0.00)\end{array}$ & 5 \\
\hline $40-49$ & $\begin{array}{c}2 \\
(28.57)\end{array}$ & $\begin{array}{c}5 \\
(71.43)\end{array}$ & $\begin{array}{c}0 \\
(0.00)\end{array}$ & $\begin{array}{c}0 \\
(0.00)\end{array}$ & 7 \\
\hline $50-59$ & $\begin{array}{c}5 \\
(20.83) \\
\end{array}$ & $\begin{array}{c}5 \\
(20.83) \\
\end{array}$ & $\begin{array}{c}3 \\
(12.50) \\
\end{array}$ & $\begin{array}{c}11 \\
(45.83) \\
\end{array}$ & 24 \\
\hline $60+$ & $\begin{array}{c}2 \\
(10.00) \\
\end{array}$ & $\begin{array}{c}7 \\
(35.00) \\
\end{array}$ & $\begin{array}{c}1 \\
(5.00) \\
\end{array}$ & $\begin{array}{c}10 \\
(50.00) \\
\end{array}$ & 20 \\
\hline Total & $\begin{array}{c}11 \\
(19.64)\end{array}$ & $\begin{array}{c}20 \\
(35.71)\end{array}$ & $\begin{array}{c}4 \\
(7.14)\end{array}$ & $\begin{array}{c}21 \\
(37.50)\end{array}$ & 56 \\
\hline
\end{tabular}


be the reason for high vascularity for larger tumours. Such findings were reported by Hsu et al ${ }^{12}$, who studied tumour angiogenesis in 141 patients with early stage cervical cancer by $3 \mathrm{D}$ power Doppler. They demonstrated that tumour vascularization correlated well with tumour volume. Testa et al ${ }^{13}$ also described a similar correlation between tumour vascularization and its volume.

In our study, we were able to demonstrate a correlation between extent of vascularity and tumour size in locally advanced cervical cancer. Similar associations were also seen with parametrial invasion and lymph node metastasis. A study done by

\begin{tabular}{|c|c|c|c|c|c|}
\hline \multicolumn{6}{|c|}{$\begin{array}{l}\text { Table 2: Relation of Tumor Volume, Lymphadenopathy } \\
\text { and parametrial invasion and Vascularity }\end{array}$} \\
\hline & \multicolumn{4}{|c|}{ Visual Grading of Vascularity } & \multirow{2}{*}{ Total } \\
\hline & 1 & 2 & 3 & $4+$ & \\
\hline \multicolumn{6}{|c|}{ TUMOR VOLUME $\left(\mathrm{cm}^{3}\right)$} \\
\hline $0-.04$ & $\begin{array}{c}6 \\
(22.22)\end{array}$ & $\begin{array}{c}9 \\
(33.33) \\
\end{array}$ & $\begin{array}{c}5 \\
(18.52) \\
\end{array}$ & $\begin{array}{c}7 \\
(25.93)\end{array}$ & $\begin{array}{c}27 \\
(100.00) \\
\end{array}$ \\
\hline $0.5-.09$ & $\begin{array}{c}3 \\
(16.67) \\
\end{array}$ & $\begin{array}{c}7 \\
(38.89) \\
\end{array}$ & $\begin{array}{c}2 \\
(11.11) \\
\end{array}$ & $\begin{array}{c}6 \\
(33.33) \\
\end{array}$ & $\begin{array}{c}18 \\
(100.00) \\
\end{array}$ \\
\hline $0.1+$ & $\begin{array}{c}0 \\
(0.00) \\
\end{array}$ & $\begin{array}{c}0 \\
(0.00) \\
\end{array}$ & $\begin{array}{c}0 \\
(0.00) \\
\end{array}$ & $\begin{array}{c}11 \\
(100.00)\end{array}$ & $\begin{array}{c}11 \\
(100.00) \\
\end{array}$ \\
\hline \multicolumn{6}{|c|}{ LYMPH NODE STATUS } \\
\hline LN + ve & $\begin{array}{c}0 \\
(0.00)\end{array}$ & $\begin{array}{c}1 \\
(6.66)\end{array}$ & $\begin{array}{c}1 \\
(6.66)\end{array}$ & $\begin{array}{c}13 \\
(86.66)\end{array}$ & $\begin{array}{c}15 \\
(100.00)\end{array}$ \\
\hline LN - ve & $\begin{array}{c}9 \\
(21.95)\end{array}$ & $\begin{array}{c}15 \\
(36.58)\end{array}$ & $\begin{array}{c}6 \\
(14.63)\end{array}$ & $\begin{array}{c}11 \\
(26.82)\end{array}$ & $\begin{array}{c}41 \\
(100.00)\end{array}$ \\
\hline \multicolumn{6}{|c|}{ PARAMETRIAL INVASION } \\
\hline +ve & $\begin{array}{c}8 \\
(17.77)\end{array}$ & $\begin{array}{c}11 \\
(24.44) \\
\end{array}$ & $\begin{array}{c}6 \\
(13.33) \\
\end{array}$ & $\begin{array}{c}20 \\
(44.44)\end{array}$ & $\begin{array}{c}45 \\
(100.00) \\
\end{array}$ \\
\hline ve & $\begin{array}{c}1 \\
(9.09)\end{array}$ & $\begin{array}{c}5 \\
(45.45)\end{array}$ & $\begin{array}{c}1 \\
(9.09)\end{array}$ & $\begin{array}{c}4 \\
(36.36)\end{array}$ & $\begin{array}{c}11 \\
(100.00)\end{array}$ \\
\hline Total & $\begin{array}{c}9 \\
(16.07)\end{array}$ & $\begin{array}{c}16 \\
(28.57)\end{array}$ & $\begin{array}{c}7 \\
(12.50)\end{array}$ & $\begin{array}{c}24 \\
(42.86)\end{array}$ & $\begin{array}{c}56 \\
(100.00)\end{array}$ \\
\hline
\end{tabular}

Chang et al in $1995^{14}$ a similar findings were shown where the vascularity index measured by Doppler correlated well with the lymphovascular space invasion rate among patients with stage Ib-IIa cervical carcinoma. In a similar study, Jurado et al ${ }^{15}$ showed that tumours with abundant vascularisation were more likely to be associated with pelvic lymph node metastasis, a depth of stromal invasion of $>10 \mathrm{~mm}$, lymph vascular space involvement, tumour diameter $>17.5$ $\mathrm{mm}$ and parametrial involvement, all predicting a poor prognosis. Greco et $a l^{16}$ also confirmed the same findings and demonstrated that the presence of colour signals on colour Doppler was associated with a higher probability of lymph node metastasis (Sensitivity - $80 \%$, Specificity - 48\%) and parametrial involvement (Sensitivity 91\%, Specificity - 57\%).

Chang-Yao Hsieh et al ${ }^{17}$ conducted a similar study by assessing the significance of intra-tumoral blood flow in stage Ib-IIb cervical carcinoma by TVCDUS and found that patients with detectable intra-tumoral blood flow exhibited significantly more pelvic node metastasis $(10 / 30 \mathrm{v} / \mathrm{s}$ $2 / 35, p=0.005)$, a higher percentage of cancer cells in $\mathrm{S}+\mathrm{G}_{2} \mathrm{M}$ phase (30.02 $\pm 18.54 \% \mathrm{v} / \mathrm{s} 19.35 \pm 11.21 \%, \mathrm{p}<$ $0.005)$ and a higher prevalence in HPV infection $(30 / 30 \mathrm{v} / \mathrm{s} 25 / 35, \mathrm{p}=0.001)$ when compared with those without significant intra-tumoral blood flow.

There have also been studies that showed tumour vascularity to be much more significant than lymph node status in determining the survival of patients with cancer cervix $^{18}$. Interestingly, it was found that patients with positive lymph nodes and low tumour vascularity had a better prognosis than patients with negative lymph nodes and high tumour vascularity. Therefore, tumour vascularity seems a significant determinant of outcome similar to the lymph node status or even more. .There have also been numerous studies on whether this tumour vascularity can be used to assess the response of patients to chemotherapy or radiotherapy. Pirhoen et al ${ }^{19}$ showed that a decrease in tumour vascularisation during radio therapy 
was associated with a better treatment outcome, whereas persistence of high vascularity was associated with a poor response, thus concluding that colour doppler ultrasound might be useful in early assessment of therapeutic response during radiotherapy.

Our study however had certain limitations. Firstly, the visual grading of vascularity used was observer dependent, making it a subjective measurement. Secondly, the sample size chosen was small to make any definite recommendation. Further studies with larger sample sizes are needed to throw more light on the subject. Whether or not this noninvasive and cost effective means of predicting prognosis can be used in clinical practice, in preference to other prognostic factors needs further study.

\section{CONCLUSION}

Transvaginal colour Doppler ultrasound is a useful non-invasive method to assess tumour vascularity. The vascularity of tumour correlates well with the prognostic factors of cancer cervix and this has the potential to be developed in to an independent prognostic factor.

\section{REFRENCES}

1. Ferlay J, Soerjomataram I, Ervik M, Dikshit R, Eser S, Mathers C, Rebelo $M$, Parkin DM, Forman D, Bray, F (2013). GLOBOCAN 2012 v1.0, Cancer Incidence and Mortality Worldwide: IARC CancerBase No. 11 [Internet]. Lyon, France: International Agency for Research on Cancer. Available from http://globocan.iarc.fr.

2. Bruni L, Barrionuevo-Rosas L, Albero G, Aldea M, Serrano B, Valencia S, Brotons M, Mena M, CosanoR, Muñoz
J, Bosch FX, de Sanjosé S, Castellsagué

$X$. ICO Information Centre on HPV and Cancer (HPVInformation Centre). Human Papillomavirus and Related Diseases in India. Summary Report 2015-03-20. [Data Accessed]

3. Folkman J. Angiogenic factors. Science 1987;235:442-5.

4. Srivastava A, Laidler P, Davies RP, Horgan K, Hughes LE. The prognostic significance of tumor vascularity in intermediate-thickness $\quad(0.76-4.0 \mathrm{~mm}$ thick) skin melanoma: a quantitative histologic study. $A m \quad J$ Pathol 1988;133:419-23.

5. Weidner N, Semple JP, Welch WR, Folkman J. Tumor angiogenesisand metastasis correlation in invasive breast carcinoma. N Engl J Med 1991;324:1-8.

6. Horak ER, Leek R, Klenk N, Lejeune S, Smith K, Stuart N, et al. Angiogenesis, assessed by platelet/endothelial cell adhesion molecule antibodies, as indicator of nodal metastasis and survival in breast cancer. Lancet 1992;340:1120 4.

7. Scappaticci FA. Mechanisms and future directions for angiogenesis-based cancer therapies J ClinOncol. 2002;20(18):390627.

8. Conway E, Collen D, Carmeliet P. Molecular mechanism of blood vessel growth. Cardiovasc Res. 2001;49:50721.

9. Drake C, La Rue A, Ferrara N. VEGF regulates cell behaviour during vasculogenesis. Dev Biol. 2000;224:17888.

10. Schoppmann S, Fenzl A, Schindl M, et al. Hypoxia inducible factor-1a correlates with VEGF-C expression and lymphangiogenesis in breast cancer. Breast Cancer Res Treat. 2006;99:13514.

11. Watanabe $Y$, Dvorak $H$. Vascular permeability factor/vascular endothelial growth factor inhibits anchoragedisruption-induced apoptosis in microvessel endothelial cells by inducing scaffold formation. Exp Cell Res. 1997;233:340-9.

12. Hsu KF, SU JM, Huang SC, Cheng YM Kang CY, Shen MR, Chang FM,Chou CY: Three-dimensional power-Doppler imaging ofearly-stage cervical cancer. Ultrasound ObstetGynecol. 2004;24:66471.

13. Testa AC, Ferrandina G, Distefano $\mathrm{M}$, Fruscella $\mathrm{E}$, Mansueto D, BassoD, Salutari V, Scambia G: Color Doppler velocimetry and three dimensional color power angiography of cervical carcinoma. Ultrasound ObstetGynecol. 2004; 24:445-52.

14. Cheng WF, Lee CN, Chu JS, Chen CA, Chen TM, Shau WY, Hsieh CY, Hsieh FJ. Vascularity index as a novel parameter for the in vivo assessment of angiogenesis in patients with cervical carcinoma. Cancer 1994; 85(3): 615-617.

15. Jurado M, Galván R, Martinez-Monge R, Mazaira $\mathrm{J}$, Luis $\mathrm{J}$. Neoangiogenesis in early cervical cancer: Correlation between color Doppler findings and risk factors. A prospective observational study. World Journal of Surgical Oncology 2008, 6:126

16. Greco $P$, Cormio $G$, Vimercati $A$, Nacci G, Di Vagnio G, Loverro G, Selvaggi L. Transvaginal color Doppler ultrasound for monitoring the response to neoadjuvant chemotherapy in advanced cervical cancer. Acta Obstet Gynecol Scand, 1997;76 : 169-72.

17. Hsieh CY, Wu CC, Chen TM, Chen CA, Chen CL, Wang JF, Chang CF, Hsieh FJ. Significance of intratumoral blood flow in cervical carcinoma assessed by color Doppler ultrasound. Cancer 1995; 75 : 2518-22.

18. Obermair A, Wanner C, Bilgi S, Speiser $P$, Kaider A, Reinthaller $A$, et al. Tumor angiogenesis in stage IB cervicalcancer: correlation of microvessel density with survival. Am J Obstet Gynecol 1998;178:314-9.

19. Pironen JP, Grenman SA, Bredbacka AB, Salmi TA. Effects of external radiotherapy on uterine blood flow in patients with advanced cervical carcinoma assessed by Doppler sonography. Cancer 1995;76:67-71. 